\title{
MORTAR SEMEN ABU DAUN PINUS DAN ABU BATA MERAH
}

\author{
Elhusna $^{\text {1) }}$, Yuzuar Afrizal ${ }^{2)}$, Halimatus Sofia ${ }^{3)}$ \\ ${ }^{1), 2)}$ Program Studi Teknik Sipil, Fakultas Teknik, Universitas Bengkulu \\ ${ }^{3)}$ Laboratorium Konstruksi dan Teknologi Beton, Fakultas Teknik, Universitas Bengkulu \\ Corresponding Author: elhusna@unib.ac.id
}

\begin{abstract}
Abstrak
Artikel ini melaporkan hasil penelitian terhadap mortar dengan tambahan $10 \%$ abu daun pinus (ADP) dengan 5 variasi abu bata merah (ABM). Mortar pada penelitian ini merupakan campuran antara pasir halus, air, dan bahan perekat berupa semen dengan perbandingan pasir dan semen 1 dan 3. ABM hingga 50\% ditambahkan dengan peningkatan $10 \%$ pada setiap variasinya Kedua jenis abu ditambahkan berdasarkan berat volume semen mortar normal. Mortar normal pada penelitian ini adalah mortar tanpa tambahan ADP dan ABM. Kubus berukuran $5 \mathrm{~cm}$ dengan rentang nilai initial flow 105\%-115\% dibuat untuk menguji kuat tekan dan absorbsi mortar. Pengujian tekan dan absorpsi mengacu pada SNI 03-6825-2002 dan SNI 15-2049-2004. Pengujian dilakukan ketika usia kubus mortar 28 hari setelah dikeluarkan dari bak perendaman sehari sebelumnya. Kuat tekan mortar terbaik terjadi pada penambahan ADP tanpa ABM yaitu lebih tinggi 22,4\% dari mortar normal. Mortar dengan ADP dan 10\% ABM memiliki kuat tekan lebih tinggi 4,4\% dari mortar normal dan lebih rendah $18 \%$ dari mortar ADP tanpa ABM. Nilai absorpsi mortar terkecil $(11,68 \%)$ terjadi pada mortar ADP dengan $10 \%$ ABM. Penelitian ini memperlihatkan bahwa nilai absorbsi mortar tidak selalu berbanding terbalik dengan kuat tekannya
\end{abstract}

Kata kunci: mortar, abu daun pinus, abu bata merah, kuat tekan, absorpsi

\begin{abstract}
This article is a report research of mortar with 10\% Pine leaf ash (PLA) and 5 variations of red brick ash (RBA). The mortar is a mixture of fine sand, water, and adhesive material with proportion of cement and fine sand is 1 dan 3. RBA was added up to 50\% of cement with $10 \%$ addition for each variation. Both of the ashes were added base on the weight volume of cement of normal mortar. The normal mortar is the mortar without the ashes. The initial flow of the mortar is 105\%-115\%. The $5 \mathrm{~cm}$ mortar cubes were made to test the compressive strength and the absorbtion. The tests were done according to SNI 03-6825-2002 and SNI 15-2049-2004 when the speciments age is 28 days. The cube speciments were taken out of the water sink a day earlier. The highest compressive strength is $22,4 \%$ higher than the normal mortar come out of the PLA mortar without RBA. The strength of the PLA and 10\% RBA mortar is 4,4\% higher than the normal one and 18\% lower then the PLA mortar without the RBA. The lowest mortar absorbtion $(11,68 \%)$ belongs to PLA mortar with 10\% RBA. The research result shows that the absorbtion and the compressive strength of the mortar isnot always inversely propotional.
\end{abstract}

Keywords: mortar, pine leaf ash, red brick ash, compressive strength, absorption 


\section{PENDAHULUAN}

Mortar adalah campuran antara pasir halus, air, dan bahan perekat dengan proporsi tertentu. Bahan perekat yang umum dipakai adalah semen. Mortar digunakan sebagai perekat antara batu pecah pada pondasi, dan pasangan bata untuk dinding. SNI 03-68252002 menyebutkan bahwa kuat tekan mortar dipengaruhi oleh kepadatan, jenis semen, umur mortar, dan sifat agregat.

\section{Daun pinus}

Pinus (Pinus merkusii Jung et de Vriese) merupakan jenis pohon yang berdaun jarum termasuk dalam family Pinaceae. Pinus merkusii merupakan satu-satunya pinus asli dari Indonesia. Daun pinus memiliki bagian pangkal dan ujung hampir sama dengan panjang sekitar 10-20 cm. Daun pinus memiliki ujung daun berbentuk meruncing, memiliki tepi berupa daun berbentuk rata serta ranting daun berukuran pendek yang berbentuk seperti jarum (Heru, 2016).

Daun pinus kering biasa terlihat bertumpuk di bawah Pohon Pinus (Gambar 1). Pohon Pinus merupakan pohon yang umum terdapat di sepanjang pantai dan digunakan sebagai tanaman penghijauan.

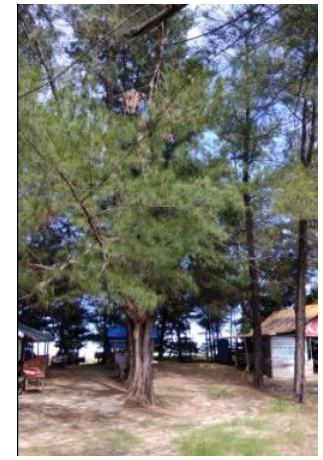

a

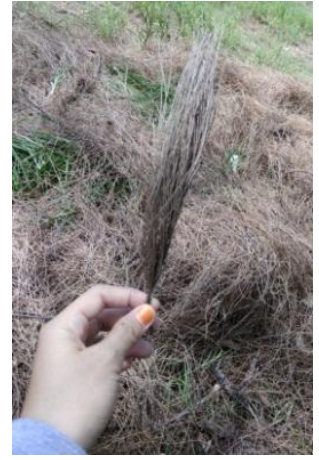

b
Gambar 1. Pohon dan Daun Pinus

Abu daun pinus diketahui mengandung selulosa antara 12,31\%-18,54\% (Wiyono dan Lukman, 1989). Selulosa pada daun
Pinus yang direndam dengan larutan kapur 5\% membentuk Kalsium Karbonat ketika dibakar dan berfungsi sebagai zat perekat (tobermorite) yang ketika bereaksi dengan semen akan semakin merekatkan butir-butir agregat sehingga terbentuk massa yang kompak dan padat (Nurmawati, 2006). Dengan demikian abu daun Pinus potensial digunakan sebagai bahan penambah semen.

Semen portland dilaporkan Irawan (2017) memiliki dua penyusun utama yaitu $22,03 \%$ $\mathrm{SiO}_{2}$ (silika dioksida) dan 58,55\% $\mathrm{CaO}$ (kalsium oksida). Abu bata merah merupakan bahan pozzolan dengan unsur silika yang akan membentuk zat perekat apabila ditambahkan pada reaksi antara semen dan air (Wikana dan Gulo, 2012).

Penggunaan abu bata merah sebagai semen merah yang berasal dari limbah bata merah (40\%) dan bata merah baru (60\%) pada mortar dilaporkan menghasilkan nilai kuat tekan mortar sebesar 28,74 MPa. Kuat tekan mortar semen bata merah yang berasal dari bata baru dan limbah bata merah tidak berbeda nyata (Nurlina, dkk, 2014).

Artikel ini melaporkan hasil penelitian terhadap kuat tekan dan absorbsi mortar dengan penambahan abu daun pinus (Pinus merkusii Jung et de Vriese) dan abu bata merah. Perbandingan semen dan pasir halus yang digunakan adalah 1 dan 3. Penambahan $10 \%$ abu daun pinus dan abu bata merah dengan variasi $0 \%, 10 \%, 20 \%, 30 \%, 40 \%$, dan $50 \%$ dilakukan terhadap volume semen.

\section{Bata merah}

Bata merah adalah bahan bangunan sejenis batako yang terbuat dari tanah liat dan dibakar pada suhu $>700{ }^{\circ} \mathrm{C}$. Tanah liat merupakan bahan utama pembuatan batu merah. Jika dicampur dengan air, maka adonan menjadi plastis dengan tingkat plastisitas yang tergantung dari jenis tanah 
liatnya. Jika dicampur dengan air, maka adonan menjadi plastis dengan tingkat plastisitas yang tergantung dari jenis tanah liatnya.

\section{Agregat halus}

Agregat halus adalah agregat dengan besar butir maksimum 4,76 mm (No.4) berasal dari alam atau buatan (SNI 03-6820-2002).

\section{Semen portland}

Semen portland adalah semen hidrolis yang dihasilkan dengan cara menggiling terak semen portland terutama yang terdiri atas kalsium silikat. Kalsium silikat yang bersifat hidrolis dan digiling bersama-sama dengan bahan tambahan berupa satu atau lebih bentuk kristal senyawa kalsium sulfat dan boleh ditambah dengan bahan tambahan lain (SNI 15-2049-2004).

\section{METODE PENELITIAN}

Penambahan abu daun pinus dan abu bata merah pada mortar dengan proporsi 1 bagian semen dan 3 bagian pasir dilakukan terhadap volume semen. Penambahan $10 \%$ abu daun pinus dan abu bata merah hingga 50\% dengan variasi peningkatan $10 \%$. Benda uji kubus mortar untuk mendapatkan kuat tekan dan absorpsi.

Daun pinus yang digunakan adalah daun pinus kering (Gambar 1b) yang telah berguguran dan biasanya memenuhi bagian bawah pohon. Daun tersebut dikumpulkan dan dibersihkan lalu dicuci hingga tidak mengandung pasir dan kotoran lainnya lalu direndam selama 24 jam dengan larutan 5\% kapur. Daun pinus selanjutnya ditiriskan dan dijemur hingga kering. Pembakaran daun pinus dilakukan hingga menjadi selama 20 menit. Abu yang digunakan pada penelitian ini adalah abu yang lolos saringan no 100 (Gambar 2).

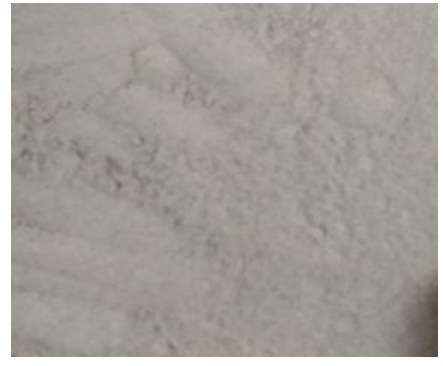

Gambar 2. Abu Daun Pinus

\section{Pembuatan kubus mortar}

Material yang digunakan adalah semen, pasir halus, abu daun Pinus (ADP), dan abu bata merah (ABM). Karakteristik bahan tersebut diuji (Tabel 1 dan 2) mengikuti standar yang berlaku. Proporsi campuran bahan pembentuk kubus mortar untuk setiap variasi (Tabel 3) dihitung berdasarkan bahan pembentuk mortar normal. Mortar normal pada penelitian ini adalah mortar tanpa tambahan ADP dan ABM. Mortar normal memiliki perbandingan volume satu semen dan 3 pasir.

Air yang digunakan pada penelitian ini memenuhi SNI 03-2847-2002. Air diamati secara visual terlihat bersih dan bebas dari bau. Jumlah air yang digunakan dibatasi dengan mengatur penggunaan air sehingga initial flow berada pada rentang yang direncanakan (105\%-115\%). Initial flow dilakukan menurut SNI 03-6822-2002.

Pembuatan kubus mortar dimulai dari penimbangan bahan sesuai perencanaan (Tabel 3). Pengadukan bahan menggunakan mixer mortar dilakukan hingga kelecakan tercapai. Kelecakan adukan dilihat dari nilai initial flow. Adukan selanjutnya dicetak setelah kelecakannya tercapai. Cetakan kubus mortar dibuka setelah 24 jam, kemudian dilakukan perendaman dalam bak yang berisi air. Kubus mortar direndam selama 26 hari dan dikeluarkan dari bak ketika kubus mortar berumur 27 hari. 
Cetakan kubus yang digunakan pada penelitian ini terbuat dari kayu. Penggunaan cetakan dari papan kayu ini dimaksudkan untuk dapat melakukan pencetakan kubus serentak untuk setiap variasi benda uji.

\section{Pengujian kuat tekan mortar}

Pengujian kuat tekan mortar dilakukan sesuai dengan SNI-03-6825-2002 dan SNI 15-2049-2004. Pengujian kuat tekan kubus mortar dilakukan setelah pengukuran dimensi dan penimbangan beratnya. Uji tekan dilakukan ketika umur kubus mortar 28 hari menggunakan alat uji tekan berkapasitas $250 \mathrm{kN}$ dan ketelitian $0,5 \mathrm{kN}$. Nilai beban yang digunakan adalah nilai maksimum yaitu nilai beban ketika kubus mortar hancur. Nilai kuat tekan mortar adalah perbandingan beban maksimum yang bekerja dan luas penampang kubus mortar.

\section{Pengujian absorpsi mortar}

Pengujian absorpsi mortar dilakukan saat kubus mortar berumur 28 hari. Kubus mortar dikeluarkan dari bak perendaman dan dilap seluruh permukaannya sampai tidak ada lagi air yang menetes. Penimbangan kubus mortar tersebut dicatat sebagai massa basah $\left(m_{b}\right)$. Selanjutnya kubus mortar dioven selama 24 jam dengan suhu $110{ }^{\circ} \mathrm{C}$. Berat kubus mortar setelah dioven adalah massa kering $\left(\mathrm{m}_{\mathrm{k}}\right)$. Nilai absorpsi mortar perbandingan dari selisih berat basah dan kering dengan berat keringnya dalam persen. Pengujian absorbsi dilakukan diadaptasi dari pengujian absorbsi benda uji beton yang dilakukan oleh Ratnaningsih, dkk (2014).

Tabel 1. Hasil Pemeriksaan Uji Sifat Fisis Agregat Halus

\begin{tabular}{clcccc}
\hline No & Nama Pemeriksaan & Hasil & Standar & Syarat & Keterangan \\
\hline 1 & MHB $(\%)$ & 1,67 & SNI 03-1968-1990 & $1,5-3,8$ & Memenuhi \\
\hline 2 & Kadar Air $(\%)$ & 3,16 & SNI 03-1971-1990 & - & - \\
\hline 3 & Berat Jenis & 2,67 & SNI 03-1970-1990 & $2,5-2,7$ & Memenuhi \\
\hline 4 & Penyerapan $(\%)$ & 1,47 & SNI 03-1970-1990 & - & - \\
\hline 5 & Berat Volume $\left(\mathrm{gr} / \mathrm{cm}^{3}\right)$ & 1,44 & SNI 03-4804-1998 & $>1,2$ & Memenuhi \\
\hline 6 & Kadar Lumpur $(\%)$ & 0,83 & SNI 03-4142-1996 & Maks 5\% & Memenuhi \\
\hline 7 & Kadar Organik & No.5 & SNI 03-2816-1992 & Maks No.11 & Memenuhi \\
\hline
\end{tabular}

Tabel 2. Nilai Sifat Fisis Abu Daun Pinus, Abu Bata Merah, dan Semen

\begin{tabular}{llccc}
\hline \multirow{2}{*}{ No } & Jenis Pemeriksaan & \multicolumn{3}{c}{ Nama Material } \\
\cline { 3 - 5 } & & Abu Daun Pinus (ADP) & Abu Bata Merah (ABM) & Semen \\
\hline 1 & Kadar Air $(\%)$ & 2,70 & 1,23 & - \\
\hline 2 & Berat Volume $\left(\mathrm{gr} / \mathrm{cm}^{3}\right)$ & 0,43 & 0,85 & 1,10 \\
\hline
\end{tabular}


Tabel 3. Bahan Pembentuk 1 Kubus Mortar untuk Setiap Variasi Abu

\begin{tabular}{|c|c|c|c|c|c|c|c|}
\hline No & \multicolumn{2}{|c|}{ Variasi Abu (\%) } & \multicolumn{5}{|c|}{ Berat Material Pembentuk Mortar (gram) } \\
\hline & Daun Pinus & Bata Merah & Pasir & Semen & Air & $\mathrm{ABM}$ & ADP \\
\hline 1 & 0 & 0 & 135 & 34,38 & 25,79 & 0,00 & 0,00 \\
\hline 2 & 10 & 0 & 135 & 34,38 & 25,79 & 0,00 & 1,35 \\
\hline 3 & & 10 & 135 & 34,38 & 25,79 & 2,66 & 1,35 \\
\hline 4 & & 20 & 135 & 34,38 & 25,79 & 5,31 & 1,35 \\
\hline 5 & & 30 & 135 & 34,38 & 25,79 & 7,97 & 1,35 \\
\hline 6 & & 40 & 135 & 34,38 & 25,79 & 10,63 & 1,35 \\
\hline 7 & & 50 & 135 & 34,38 & 25,79 & 13,29 & 1,35 \\
\hline \multicolumn{3}{|c|}{ Total } & 945 & 240,66 & 180,53 & 39,86 & 8,10 \\
\hline
\end{tabular}

\section{HASIL DAN PEMBAHASAN}

Berat isi, kuat tekan dan absorpsi menjadi karakteristik mortar yang dilaporkan. Karakteristik Berat isi mortar terlihat tidak dipengaruhi oleh variasi abu yang digunakan (Gambar 3) jika dibandingkan dengan nilai berat isi mortar normal (Tabel 3). Berat isi mortar normal $4 \%$ lebih besar dari mortar dengan 10\% ADP tanpa ABM (Gambar 4).

Kuat tekan mortar normal terjadi pada penambahan $10 \%$ abu daun pinus tanpa abu bata merah (Gambar 3). Kuat tekan mortar normal 22,4\% lebih rendah dari pada kuat tekan mortar dengan ADP saja. Kuat tekan terkecil mortar dengan ADP (Gambar 4) terjadi pada penambahan $40 \%$ ABM yaitu $31,2 \%$ lebih kecil dari kuat tekan mortar dengan ADP tanpa ABM.

Tabel 3. Karakteristik Mortar Normal

\begin{tabular}{rrr}
\hline $\begin{array}{l}\text { Berat isi } \\
\left(\mathrm{gr} / \mathrm{cm}^{3}\right)\end{array}$ & $\begin{array}{c}\text { Kuat Tekan } \\
(\mathrm{MPa})\end{array}$ & \multicolumn{2}{l}{$\begin{array}{l}\text { Absorbsi } \\
(\%)\end{array}$} \\
\hline 1.98 & 10.31 & 12.68 \\
\hline
\end{tabular}

Karakteristik mortar setiap variasi dibandingkan dengan karakteristik mortar dengan tambahan ADP tanpa ABM memperlihatkan bahwa kuat tekan mortar dengan ADP menurun ketika ditambah ABM (Gambar 4). Mortar dengan ADP dan ABM masih lebih tinggi dari mortar normal ketika ABM ditambahkan 10\%. Mortar ADP memiliki nilai absorbsi yang menurun ketika ABM ditambahkan $10 \%$ dan kembali meningkat seiring dengan penambahan ABM.

Berat isi mortar terbesar dan kuat tekan terendah terjadi pada mortar ADP dengan 30\% ABM. Sedangkan Absorbsi terbesar dimiliki oleh mortar ADP dengan 50\% ABM yaitu 3,8\% lebih tinggi dari pada absorbsi mortar normal.

Peningkatan dan penurunan kuat tekan mortar kemungkinan terjadi karena pengaruh absorpsi, dimana ketika nilai absorpsi meningkat maka nilai kuat tekan menurun. Grafik (Gambar 4) menunjukkan nilai kuat tekan terbesar terjadi tanpa penambahan abu bata merah sedangkan nilai absorpsi terkecil terjadi pada penambahan $10 \%$ abu bata merah. Penelitian ini menunjukkan bahwa hubungan antara kuat tekan dan absorpsi mortar tidak selalu berbanding terbalik. 


\section{Karakteristik Mortar}

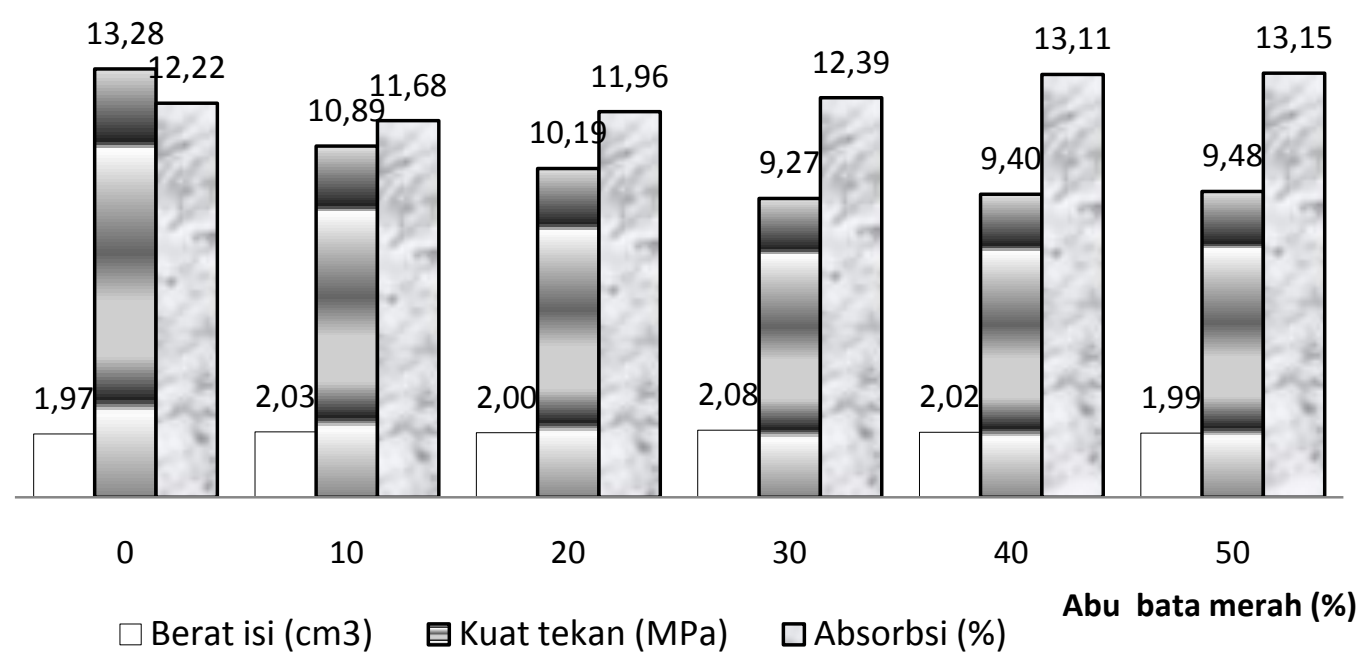

Gambar 3. Perilaku Karakteristik Mortar Semen Abu Bata Merah dan Daun Pinus

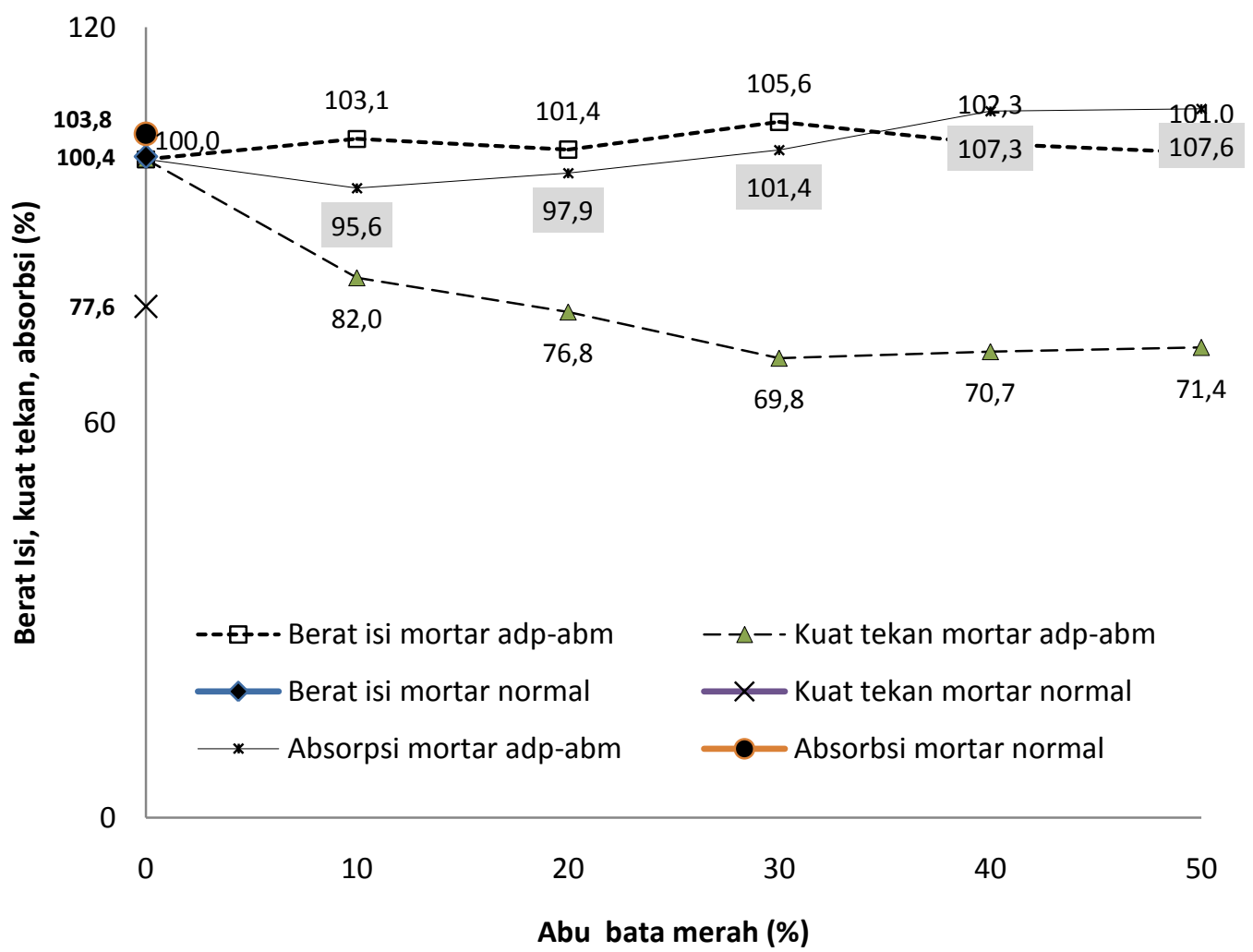

Gambar 4. Rasio Karakteristik Mortar 


\section{KESIMPULAN}

Penggunaan $10 \%$ abu daun Pinus meningkatkan kuat tekan mortar. Kuat tekan mortar abu daun Pinus menurun ketika ditambahkan abu bata merah. Kuat tekan mortar dengan tambahan $10 \%$ abu daun Pinus dan $10 \%$ abu bata merah lebih besar dari mortar normal.

Absorpsi mortar menurun dengan penambahan ADP dan semakin menurun dengan penambahan $10 \%$ abu bata merah. Penambahan abu bata merah berikutnya kembali meningkatkan nilai absorpsi mortar.

Penelitian ini perlu dilanjutkan untuk melihat perilaku mortar dengan abu daun pinus dan abu bata merah. Perilaku kuat tekan dan absorpsi mortar yang tidak selalu berbanding terbalik masih memerlukan kajian lebih lanjut.

\section{DAFTAR PUSTAKA}

Fauzi, M.F., 2014. Pemanfaatan Limbah Serbuk Kayu (Sawdust) sebagai Subtitusi Agregat Halus pada Campuran Beton. Jurnal Teknik Sipil USU,3(2). pp. 1-7.

Irawan, R.R., 2017. Kajian Sifat Kimia, Fisika, dan Mekanik Semen Portland di Indonesia (Assesment Of Chemical, Physical, and Mechanical Properties of Indonesian Portland Cements). Jurnal Jalan-Jembatan, 34(2), pp.79-90.

Nurmawati, I., 2006. Pemanfaatan limbah Industri Penggergajian Kayu Sebagai Bahan Subtitusi Pembuatan Paving Block. Skripsi, Universitas Negeri Semarang, Semarang.

Nurlina, S., Hidayat, T., Suseno, H. and Kharisma, E.M., 2015. Pengaruh Penggunaan Limbah Batu Bata sebagai Semen Merah terhadap Kuat Tekan dan Kuat Tarik Mortar. Rekayasa Sipil, 8(2), pp.136-141.

Ratnaningsih, A., Badriani, R.E. and Arifin, S., 2014. Pengaruh Penambahan Sekam Padi pada Campuran Beton Ringan Non
Struktural terhadap Nilai Penyerapan dan Nilai Kuat Tekan Beton Campuran Semen, Kulit Kopi, dan Flyash. pp. 5056.

SNI 03-1968-1990. Metode Pengujian Analisis Saringan Agregat Halus dan Kasar. Departemen Pekerjaan Umum Yayasan Badan Penerbit PU.

SNI 03-1970-1990. Metode Pengujian Berat Jenis dan Penyerapan Air Agregat Halus. Departemen Pekerjaan Umum Yayasan Badan Penerbit PU.

SNI 03-1971-1990. Metode Pengujian Kadar Air Agregat. Departemen Pekerjaan Umum Yayasan Badan Penerbit PU.

SNI 03-2816-1992. Metode Pengujian Kotoran Organik dalam Pasir untuk Campuran Mortar dan Beton. Departemen Pekerjaan Umum Yayasan Badan Penerbit PU.

SNI 03-4142-1996. Metode Pengujian Jumlah Bahan dalam Agregat yang Lolos Saringan No.200 (0,075 mm). Departemen Pekerjaan Umum Yayasan Badan Penerbit PU.

SNI 03-4804-1998. Metode Pengujian Bobot Isi dan Rongga Udara dalam Agregat. Departemen Pekerjaan Umum Yayasan Badan Penerbit PU.

SNI 03-6825-2002. Metode Pengujian Kekuatan Tekan Mortar Semen Portland untuk Pekerjaan Sipil. Departemen Pekerjaan Umum Yayasan Badan Penerbit PU.

SNI 03-6882-2002. Spesifikasi Mortar untuk Pekerjaan Pasangan. Departemen Pekerjaan Umum Yayasan Badan Penerbit PU.

SNI 15-2049-2004. Semen Portland. Badan Standardisasi Nasional.

SNI 15-7064-2004. Semen Portland Komposit. Badan Standardisasi Nasional.

Wikana, I. and Gulo, D., 2012. Pengaruh Penambahan Tumbukan Batu Bata Merah dan Pengurangan Semen terhadap Kuat Tekan Serta Keausan Paving Block. Majalah Ilmiah UKRIM Yogyakarta. Universitas Kristen Immanuel Yogyakarta. 
Mortar Semen Abu Daun Pinus dan Abu Bata Merah

Wiyono, B. and Lukman, A.H., 1989.

Analisis Kimia Daun Pinus dan

Pemanfaatannya. Jurnal Penelitian

Hasil Hutan, 6(2), pp.125-128. 